\title{
MANAGING DISTRIBUTED UNIVERSITY COURSES
}

\author{
Kirsti Ala-Mutka and Sanna-Maria Räisänen \\ Tampere University of Technology, Institute of Software Systems
}

\begin{abstract}
The Open Source Courseware project $(\mathrm{OSCu})$ is aimed at cooperative course development and implementation in university software-engineering education. Open materials and a distributed course implementation model offer effective means for knowledge sharing between universities. However, in practice there are many difficulties in managing distributed courses and the actual cooperation scheme. This article presents the major problems faced in the first four distributed courses, and the approaches that were developed and which are now used to deal with them.
\end{abstract}

Key words: Higher education, experimental, open systems, resources, distributed courses

\section{INTRODUCTION}

Software-engineering education in universities often faces a lack of teaching personnel because of the large number of students and the large scope covered by its constituent teaching subjects. Further, the whole field of software-engineering is constantly developing and courses need to be continuously updated, and new ones created, in order for the university to be able to provide an up-to-date education that develops requisite professional knowledge in its software-engineering graduates. These problems led to a cross-university cooperative project to find solutions to them. The Open Source Courseware $(\mathrm{OSCu})$ project lets universities share the work of developing courses and thus more easily increase the number of different courses for students. Courses are also implemented by distributing tutoring materials among all participating universities.

This paper describes experiences and problems that have been met during these courses and the practices that have been developed to deal with the 
problems. Section 2 introduces briefly the principles of the Open Source Courseware Project. Section 3 presents the most important experiences and problems that have been faced in managing the project. Section 4 presents the practices and solutions that have been planned and implemented to improve the working practices in the project.

\section{THE OPEN SOURCE COURSEWARE PROJECT}

The OSCu project consists of two major components, a course material bank and a distributed course implementation model for the concurrent use of course materials by several universities at the same time. Individual course material production and development is also encouraged. The aim is to pursue university course development practices that are similar to those in the open source software development environment, so that anyone can further develop existing solutions.

It is not uncommon to publish course materials so as to make them available for others. Many universities have been doing this for years in their course web pages. Currently, there are several initiatives that produce and deliver course materials and packages both for contact education and webbased learning solutions, e.g. MIT OpenCourseWare (MIT, 2003) and UNIVERSAL (UNIVERSAL, 2003). The goals of the OSCu materials are, however, more extensive. The project aims to provide enough information for another teacher to really take the course, teach it to students, and develop it further. The teaching materials are equipped with documents regarding their intended use, experiences, and feedback received from the course as well as metadata descriptions of the contents.

However well-documented the materials are, they may still not contain enough information for a teacher who is unfamiliar with the subject or has never seen the materials in use. For this reason, a distributed course model was developed to offer universities the possibility to become acquainted with the issues related to the course in practice. In this model, one university is responsible for designing the course, developing and updating the materials for it, controlling the progress of the course and implementing the lectures via videoconferencing for all universities. The remote universities have local tutoring assistants to take care of the local organizing issues, exercise sessions, and all tutoring tasks for their students.

With this model, remote universities can offer their students courses that they could not have developed themselves. The local tutoring assistant receives the teaching materials and instructions for the teaching situation from the organizing university. After a few years of participating in a course in this fashion, the assistant has enough knowledge for organizing the course 
by her/himself. In this way, students and teachers at the remote universities get new knowledge and the lecturer at the organizing university receives versatile feedback for developing the course in the future. With welldocumented materials, it is also possible to transfer courses between universities so that the materials get updated and improved also by other persons than the original creators.

The project organization has two levels. The executive group consists of representatives from all the universities in the project and its main task is to decide the guidelines and funding issues for the project. Each course is a subproject, managed by the organizing university. The organizing university is responsible for all the issues related to the general organizing, designing, and implementation of the course. Remote universities are responsible for carrying out their part of the tutoring, reporting, and feedback collection according to the given instructions. The OSCu project coordinator develops guidelines and ensures that all the actors have a correct understanding of the project goals and guidelines and of their tasks on the courses.

More information on the project ideas, technical implementation, and experiences can be found in Ala-Mutka \& Mikkonen (2002).

\section{PROBLEMS IN IMPLEMENTING DISTRIBUTED COURSES}

During the first year of the project, three universities organized altogether four courses, all of them having two participating universities. Since the easiest way to introduce new kinds of teaching models is to create new courses, the course topics were selected so that each university presented a course that was not on the curriculum of the other universities. This demonstrated well the sharing and delivering of new knowledge, but also created many practical problems.

One of the big problems with distributing education for different persons is ensuring the same level of tutoring and guidance for all students. With new courses, the problem becomes magnified if the tutoring assistant in the other university does not have much previous knowledge of the topic. She/he may also lose interest in the tutoring task if she/he does not feel well enough prepared for the task.

Another problem stems from the lecture arrangements. If some students watch the lecturer on a screen while others have her/him present, it is clear that they have a different experience. If the lecture's teaching style and the local tutoring assistant are not activating the remote students, the latter may feel they are just watching a TV show with no motivation to really 
concentrate on the issue. Also technical problems bother remote students more than local ones.

One problem was the lack of understanding of the larger goals of the project and thus lack of motivation among the teaching personnel to follow the given guidelines for course practice. Some teachers did not see their work as much more than dealing with their local student group and were not motivated to participate in or implement coordinating actions with others. This caused problems of course uniformity and was also seen in the final examination results, where the differences between local students' grades and the remote students' grades were obvious on some of the courses.

There were often problems in preparing the practical matters for the courses. Information on some relevant issues was decided or communicated to the participating universities so late that all the course arrangements could not be implemented in time or at all. There were problems with e.g. differing lecture periods, lecturing times, the software platform for coursework, and communication practices on the course. Also unclear roles of the teaching personnel often made it difficult to sort out these issues.

Course documentation and materials were archived and documented poorly on many courses and some teaching materials are still missing from the archive. Also the implementation process of courses was sometimes poorly documented, although all lecturers agreed to document their course according to the given precise guidelines. Sometimes also the assistants did not receive enough instructions for their work, and thus the lecturer had to do some tutoring and evaluation work by her/himself for all the universities.

These problems also led to the new challenge of organizing the coordination in the future with a larger number of participating universities. The project coordinator had to spend a lot of time ensuring that course lecturers and universities organizing a course completed their tasks as well as necessary. When continued this way, for every new 5 universities and courses a new coordinator is needed to make sure that the universities and teachers are aware of and motivated to take care of all their tasks.

\section{IMPROVING THE PRACTICES}

For managing a course that is distributed to several universities and persons, it is very important to have a common understanding of the goals and the work to be done. Like in a multi-site software project, this requires careful planning, documentation, and continuous communication between all the project partners. However, all the persons in the project do not necessarily see the relevance of the strictly defined guidelines or the additional tasks, compared with their normal tutoring work. For this reason, 
the guidelines were refined and new ones were created to motivate and offer information on each teacher's role in the project.

A balanced distribution of actions and responsibilities with well-defined practices for all the participating universities is required for this kind of activity to stabilize as a part of normal university education. For this reason, the project practices are being developed toward a model in which only minimum central coordination is needed. Most of the course-related work is already financed with participating universities' own resources, which makes it easier to change later to completely self-financed operation.

\subsection{Course level management}

One of the big problems in the courses was lack of clarity with personal responsibilities. The working model was new for most of the course teachers and they could not comprehend all the tasks required of them. To make these issues clear, the coordinator created instructions of the course actor roles and the tasks belonging to them for both organizing and remote universities. These instructions list all the main tasks that are required in carrying out a distributed course, e.g. by a "lecturer" or by a "remote lecture assistant".

One of the main problems was the coordination of the course, partly due to the unclear tasks and roles and partly because these tasks were distributed between many persons. For more structured management and less work for the organizing university, each university partner on the course is now required to assign a "coursemaster" who is responsible for the local arrangements of the course. She/he is the contact person in all course-related matters and delivers information and tasks forward to the organizing university or to the local tutoring assistants as she/he sees necessary.

Designing and organizing a course involves plenty of work in itself and the experience has shown that a lecturing professor seldom has time for any extra work. For this reason, we suggested that in every OSCu course the coursemaster at the organizing university should also take care of all the $\mathrm{OSCu}$ project-related extra work issues on the course. Thus, she/he should take care of the most of the coordination issues, course material archiving, and metadata descriptions. The lecturer can concentrate on designing a course and methods of teaching it, and his workload does not increase significantly due to the distributed course implementation. This is especially important on new courses, where the contents and materials are created from scratch, which requires lots of time for material development.

For improving internal course communication, weekly meetings and opening and closing seminars for the whole course personnel are now required for all courses. To ensure that all necessary issues are covered for these situations, the coordinator has provided general agenda suggestions. 
There are also guidelines for organizing communication outside the meetings through course masters. This provides the fastest answers regarding local issues and gives students and local tutoring assistants a dedicated contact person for problem situations with time to answer questions.

\subsection{Project level coordination and control}

$\mathrm{Al}$ of the project's instructions and guidelines are documented in written form and made available to all OSCu partners. This is important for communicating the practices pursued in the project, and to make them clear to all participating personnel. The coordinator actively follows and evaluates courses and gathers information and experiences to continuously improve these instructions. There are guidelines e.g. for planning and acting in videoconference situations, for course organizational issues, for documenting course materials, and for reporting course implementation.

Many of these documents were available when the courses started. However, not all of the course personnel read them well enough, or at all. Subsequently we have implemented a mandatory 1-day orienting seminar for the key people involved in all of the courses - to ensure that they do become familiar with the project's ideas, nature and practices, The coordinator participates in the seminar, providing brief training on the project and its procedures and checking that the personnel addresses all the necessary crucial course issues at the beginning of the course.

Material archiving was the biggest problem on many courses. Particularly in the case of new courses, the creating of the materials was so laborious that the lecturers had no time to document the materials and the course implementation thoroughly. This problem is partly addressed by assigning the material archiving tasks to the coursemaster. Practice has suggested that it also should be monitored during the course. Now the material archiving is required to be completed at least after every 1-credit subunits of a course. It is also recommended that the course archive be published for OSCu partners so that they are able to follow its development. In this way, the materials have to be documented and archived little by little and this work does not pile up at the end of the course.

Preparing a distributed course requires taking care of many small details, especially in the case of new courses. A checklist of all the crucial tasks placed in a timeline was implemented as a tool for all universities that need to prepare for a course. The checklist contains issues like "adjust the lecture periods, inform about the needed software, decide the roles for the course personnel, create course webpages", etc. These tasks cover the main points 
that have been noticed to be important from a practical point of view for $\mathrm{OSCu}$ course preparation in both the organizing and remote universities.

\subsection{Motivation}

One of the big problems in implementing courses was that the personnel was not prepared or motivated to do all the tasks expected of them. This was partly due to the fact that they were not that familiar with the whole project and could not understand their part in it. The tasks are now more clearly defined in the instruction guidelines and the motivation problem is approached by the personal visit of the coordinator to the opening seminar for each course. She takes care of introducing the basis and goals of the whole project, explains the need for the specified practices, and emphasizes the importance of each project member in achieving the common goals.

One of the most common demotivating factors in 2002 was the lack of time. OSCu-related issues were often expected to be carried out in addition to the teachers' normal tasks. Therefore, an approximation of the needed working hours was made for each of the personnel roles. The approximation serves two purposes. It clarifies for people in advance how much work they are expected to invest, and it functions as a basis for teachers in negotiating their total workload with the manager of their department.

Another reason for the lack of motivation is that teachers do not know how to prepare themselves for this new different situation with possibly new topics. For this reason, the coordinator has prepared guidelines for the lecture situation with suggestions the student activation. Also, in the course opening seminars and weekly meetings it is suggested that the course personnel always go through the relevant topics on the course so that each tutor obtain enough knowledge and instructions for the local tutoring tasks.

The best way to motivate persons to work in a project is to involve them already in the planning, not just to implement something already decided. During the course, all teachers regularly have a possibility to suggest actions and methods for the course. They could also be offered a possibility to participate to planning the course implementation in advance. For example, distributing course work design to several universities has produced good results regarding the motivation and team spirit of the course personnel.

\section{CONCLUSION}

This paper has described problems, and approaches for solving them, in the $\mathrm{OSCu}$ project and in using its distributed course model. In order to get courses to run smoothly, people have to understand and perform all the tasks 
assigned to them. Also internal course communication and cooperation have to function smoothly throughout courses. This is essential in order to be able to provide equally good education for all the students in all the participating universities.

It is very important to motivate all the persons working in the project to see the common goals and the need for common guidelines also in their own work. The working models need to be clear, motivating, and beneficial so that every person and partner university experiences receiving something in return for the work they provide. In the future, the role of the course material bank as an instrument in coordination will be emphasized. When course materials and weekly meeting reports are actively updated for the material bank during a course, the personnel can always be aware of the current situation regarding the course and the tasks expected of them.

The described management practices have shown positive effects on OSCu courses during Spring 2003. The practices are also being implemented and evaluated with a special care on an example course for creating proper working guidelines for the personnel on other courses. Developing the management of distributed courses requires comprehensive feedback from all the participants in the project. In the future, the role of feedback will be more emphasized and gathered systematically from both students and all course personnel in order to ensure continuous development of the practices.

\section{REFERENCES}

Ala-Mutka, K. \& Mikkonen, T. (2002). Experiences with Distributed Open Source Courses. In L. M. Ribeiro \& J. Marques dos Santos (Eds.), The Changing Universities: The Challenge of New Technologies: Proceedings of the 8th International Conference of European University Information Systems (EUNIS 2002), (pp. 26-37). Porto: Faculdade de Engenharia da Universidade do Porto

Massachusetts Institute of Technology. (2003). MIT Open Course Ware. Retrieved 27.8.2003 from http://ocw.mit.edu/.

UNIVERSAL project. (2003). Retrieved 27.8.2003 from http://www.ist-universal.org/.

\section{BIOGRAPHY}

Kirsti Ala-Mutka's main research interest is in developing computer based solutions for assessment and learning support in software engineering education. She has also been involved in creating the Open Source Courseware project for improving the quality of courses by developing staff and university cooperation. Sanna-Maria Räisänen has research interests in distance education, learning at work, and human resource management. She has been working as a developer and a coordinator in the Open Source Courseware project. 